\title{
Features of the formation of conductive films during thermal and laser sintering of silver nanoparticles stabilized by an ethoxylated carboxylic acid
}

\author{
Alexander I. Titkov ${ }^{1-}$, Inna A. Malbakhova ${ }^{1}$, Tatyana A. Borisenko ${ }^{1}$, Alexander M. \\ Vorobyev $^{l}$, Olga A. Logutenko ${ }^{1}$, Sergey G. Baev ${ }^{2}$ and Viktor P. Bessmeltsev ${ }^{2}$ \\ ${ }^{1}$ Institute of Solid State Chemistry and Mechanochemistry SB RAS, Kutateladze St. 18, Novosibirsk, \\ 630128, Russia \\ ${ }^{2}$ Institute of Automation and Electrometry SB RAS, Academician Koptyug Av. 1, Novosibirsk, \\ 630090, Russia
}

\begin{abstract}
Silver nanoparticles (Ag NPs) of $\sim 6 \mathrm{~nm}$ in size were synthesized by the reduction of silver 2-[2-(2methoxyethoxy)ethoxy]acetate by benzyl alcohol acting both as the solvent and as the reducer. The as-synthesized Ag NPs were dispersed in a mixture of nontoxic solvents with different boiling temperatures (butanol and propylene glycol ethers) to prepare ink. The ink was spin-coated on polyimide films and processed with thermal and laser sintering. After thermal sintering, the silver films have a non-uniform structure and contain many voids, causing their resistivity to be quite high $(28 \mu \Omega \times \mathrm{cm})$. Laser sintering of the Ag NPs inks spin-coated on a polyimide film using a fiber laser operating at a wavelength of $1.064 \mu \mathrm{m}$ in a pulse-periodic mode results in a uniform film structure, almost without voids, with a lower resistivity of $2.3 \mu \Omega \times \mathrm{cm}$. Laser sintering in this case is a promising method to fabricate conductive patterns on various substrates, including polymer flexible ones.
\end{abstract}

\section{Introduction}

Due to the rapid development of the printed electronics, much attention has been focused on the research and development of different types of conductive inks to fabricate conductive tracks for electronic devices, such as displays, solar cells, sensors, radiofrequency identification (RFID) tags, flexible and wearable electronics [1,2]. The metals most commonly used in the ink formulations are silver, copper, nickel, gold, aluminum and zinc [3]. Currently, silver-based conductive inks are most widely used due to the unique properties of silver, including its high electrical conductivity and oxidation resistance [315]. When formulating the inks based on silver nanoparticles (AgNPs), stabilizers and surfactants should be used to prevent the particles from aggregation and sedimentation. For

- Corresponding author: a.titkov@solid.nsc.ru 
this purpose, different molecules such as alkylamines, amides, alkylthiols, phosphorus containing surfactants, as well as polyvinylpyrrolidone (PVP) and other polymers have been widely used [3-7]. Also, a number of studies were focused on the development of inks based on silver nanoparticles stabilized by carboxylic acids with different chain lengths [811]. Unlike silver nanoparticles stabilized by polymers, the annealing of nanoparticles capped with small molecules such as amines and carboxylic acids can be carried out at lower temperatures. However, such inks have low stability because of the aggregation of the nanoparticles and require additional polymer stabilizers $[12,13]$. However, the use of both the polymer stabilizers and long chain carboxylic acids leads to an increase in the annealing temperature (generally $>200{ }^{\circ} \mathrm{C}$ ) when fabricating electrically conductive patterns. In our earlier work [15], AgNPs stabilized by an ethoxylated carboxylic acids have been prepared which can be used in ink formulations without introducing additional polymer dispersants. The annealing temperature of this ink was lower than that of AgNPs ink stabilized by the corresponding carboxylic acids.

The problem of low stability and high annealing temperature of the dispersion of nanoparticles can be overcome by using particle-free approach consisting in printing a metal salt solution or a metal-organic complexes solution as the metal-organic decomposition (MOD) inks on the substrate [12-14]. Thermal decomposition of the metalorganic complexes generally can be achieved at a lower temperature. However, because of the high content of the organic component, its subsequent decomposition and removal during thermal post-processing result in various defects of the layer, including pores and cracks, reducing its quality and electrical conductivity [16].

Printing on flexible, temperature-sensitive polymeric substrates requires a lowtemperature annealing step or using other post-treatment techniques to remove organic components and to form an electrically conductive path [3, 17-19]. Laser sintering has recently been developed as an alternative post-treatment technique [18, 19]. This method is distinguished from others by its localness and selectivity, which makes it possible to form electrically conductive patterns on complex devices, such as, organic field effect transistors (OFETs) [19]. It should be mentioned that gas and solid-state lasers with different wave length and operating in pulse or continuous mode are most often used [18, 19], while only few studies reported inexpensive and affordable diode lasers [20, 21]. Even though a large number of studies have reported the influence of the operating mode, power, scanning speed, exposure and other laser parameters on the conductivity of the resulting films, there has been very little research reported on the effect of the film structure and morphology on its electrical properties, and on the difference in the structure of the Ag NPs films obtained with thermal sintering, in particular, at close values of the layer conductivities.

In this work, silver nanoparticles of $\sim 6 \mathrm{~nm}$ in size were synthesized. The as-prepared NPs were then dispersed in a mixture of nontoxic solvents without any additional stabilizers to fabricate inks. The silver nanoparticle layers were fabricated by spin coating on polyimide polymer films using the developed silver ink, followed by sintering of the obtained elements using thermal annealing and a fiber laser operating at a wavelength of $1.064 \mu \mathrm{m}$. The structure and electrical properties of the conductive layers obtained after the laser and thermal curing have been investigated and compared.

\section{Experimental}

All reagents were used as received without further purification. High-purity silver nitrate (AgNO3, 99.9\%), sodium hydroxide $\left(\mathrm{NaOH}, 50 \%\right.$ aqueous solution), 1-butanol $\left(\mathrm{C}_{4} \mathrm{H}_{9} \mathrm{OH}\right)$, acetone, and hexane $(\geq 99.8 \%)$ were purchased from Chimmed Group, Russia. Benzyl alcohol $\left(\mathrm{C}_{6} \mathrm{H}_{5} \mathrm{CH}_{2} \mathrm{OH}\right)$ of $99.5 \%$ purity was purchased from PanReac AppliChem (Germany), 2-[2-(2-methoxyethoxy)ethoxy]acetic acid $\left(\mathrm{C}_{7} \mathrm{H}_{14} \mathrm{O}_{5}\right.$, MEEAA) (99\%), 
propylene glycol monobutyl ether $\left(\mathrm{C}_{4} \mathrm{H}_{9} \mathrm{OCH}_{2} \mathrm{CHOHCH}_{3}, \mathrm{PnB}\right)$ of $\geq 99.0 \%$ purity grade were supplied by Sigma Aldrich.

Ag nanoparticles and inks fabricated therefrom were prepared according to the published procedure [15]. For the ink preparation, $2.0 \mathrm{~g}$ of freshly synthesized silver nanoparticles were added to the mixture of $6.3 \mathrm{~g}$ of 1-butanol, $1.7 \mathrm{~g}$ of propylene glycol butyl ether, and dispersed using an IKA T-25 homogenizer for $15 \mathrm{~min}$ at a rate of $2000 \mathrm{rpm}$ followed by ultrasonication for $15 \mathrm{~min}$ using a laboratory ultrasonic bath. This procedure was repeated twice. As a result, the ink contained $20 \mathrm{wt} \%$ Ag NPs. Spin coating of the silver ink was performed by spinning an ink droplet on DuPont Kapton ${ }^{\circledR}$ polyimide film (PI) using a laboratory spin coater KW-4A at 500 RPM during 2 min.

The spin-coated films were annealed at temperatures of $150-300{ }^{\circ} \mathrm{C}$ in a laboratory oven with automatic control and maintenance of the required temperature. The sheet resistance of the film was measured by using a four-point probe system (IPU-1, Russia). For the conductive films obtained under the same conditions, the resistance measurements were averaged over three samples.

Laser sintering of the spin-coated films of Ag NPs on a polyimide using a fiber laser operating at a wavelength of $1.064 \mu \mathrm{m}$ in a pulse-periodic mode was performed in one pass regime with changeable laser power. The laser pulse duration and frequency were 4 ns and $250 \mathrm{kHz}$, respectively; the average power changed in the range 0.45-2.7 W. Exposure was carried out using the raster scanning of squares $5 \times 5,10 \times 10 \mathrm{~mm}^{2}$. The raster spacing was $0.0125 \mathrm{~mm}$, the size of the focused laser beam was $0.035-0.05 \mathrm{~mm}$ in terms of intensity $\mathrm{e}^{-2}$, scanning velocity was $250 \mathrm{~mm} / \mathrm{sec}$, so the exposure time on the point of the film with size of laser beam was $0.15-0.2 \mathrm{~ms}$.

X-ray diffraction (XRD) patterns were recorded on a D8 Advance powder X-ray diffractometer equipped with a one-dimensional Lynx-Eye detector and a $\mathrm{K} \beta$ filter using $\mathrm{Cu} \mathrm{K} \alpha$ radiation. The crystallite size and lattice parameters were estimated by the Rietveld method [22] using software for the profile and structural analysis Topas 4.2 (Bruker AXS, Germany). The broadening of the patterns due to the crystallite size was modeled by the "Double-Voigt" function. Analysis of the samples by transmission electron microscopy (TEM) was performed using a JEM 2010 electron microscope (JEOL, Japan) operating at $200 \mathrm{kV}$ and having a resolution of $0.14 \mathrm{~nm}$. The particle size distribution was calculated using TEM images on more than 200 particles. A study of the samples by scanning electron microscopy (SEM) was performed using a Hitachi $3400 \mathrm{~N}$ scanning electron microscope (Hitachi Ltd., Japan).

\section{Results and discussion}

Silver nanoparticles of $6.5 \pm 1.1 \mathrm{~nm}$ in size were synthesized by the reduction of silver nitrate by benzyl alcohol in the presence of MEEAA. The as-synthesized nanoparticles were spherical in shape with uniform size distribution (Fig. 1a). X-ray phase analysis revealed that the silver is in the metallic state, and no peaks assigned to the oxide phase were found (Fig. 1b, curve 1). There are three main characteristic peaks at $2 \theta=38.1^{\circ}, 44.1^{\circ}$, and $64.4^{\circ}$ there, corresponding to diffraction from the planes (111), (200), and (220) of the face-centered cubic (fcc) Ag (JCPDS, File No. 001-1164). Using the Rietveld method, it was shown that the as-synthesized silver metal particles have an fcc defect structure and a crystallite size of $2.5 \mathrm{~nm}$, which is in agreement with the crystallite sizes estimated from the TEM images. 

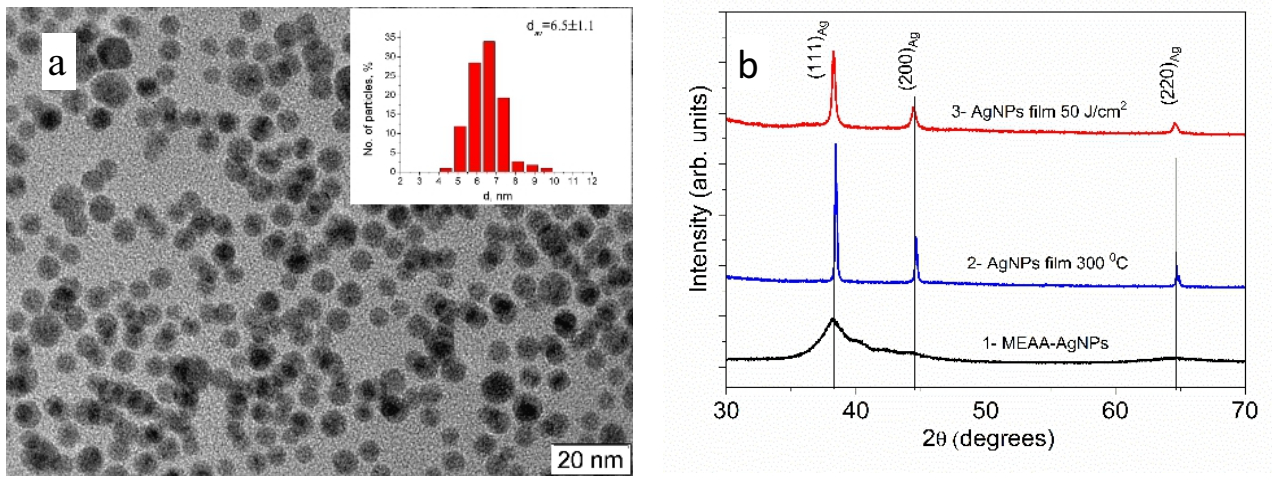

Fig. 1. TEM images and size distribution histogram of Ag NPs (a) and XRD patterns (b) of Ag NPs (1) and $\mathrm{Ag}$ NPs films after thermal sintering at $300^{\circ} \mathrm{C}(2)$ and laser sintering with the exposure 50 $\mathrm{J} / \mathrm{cm}^{2}(3)$.

The origin of the bonding between the silver nanoparticle surface and MEEAA was earlier investigated by the FTIR analysis [15]. It was found that the efficient stabilization of silver nanoparticles is due to coordination of the carboxyl group to their surface. As a result, very small nanoparticles are formed. A thermogravimetric study showed that MEEAA is started to decompose and remove from the surface of the silver nanoparticles at a temperature of $110^{\circ} \mathrm{C}[15]$.

Based on the silver nanoparticles, conductive inks containing a mixture of 1-butanol, propylene glycol monobutyl ether, and $20 \mathrm{wt} . \% \mathrm{Ag}$ have been prepared. In this work, a mixture of butanol-1 and propylene glycol ester was chosen as the solvent of ink because these reagents have high boiling points and relatively low evaporation rates, and they are commonly used in ink formulations.

The silver conductive films on polyimide substrates were obtained by spin coating of the ink with a subsequent thermal or selective laser sintering process. The average thickness of the deposited films was about $1 \mu \mathrm{m}$. To get insight into the effect of temperature on the conductivity of the films, their microstructure and resistivity at various curing temperatures were investigated. Fig. 2 shows the surface morphology of the initial films and after their curing at 150,200 and $300^{\circ} \mathrm{C}$ for $30 \mathrm{~min}$. After thermal sintering of the inks at $150^{\circ} \mathrm{C}$, the initial particles of $6 \mathrm{~nm}$ in size are sintered reaching a size of 100-200 nm (Fig. 2a, b). By increasing the temperature to $200-300^{\circ} \mathrm{C}$, the $\mathrm{Ag}$ NPs fusion with the formation of a nonhomogeneous film structure composed of large crystallites and voids occurs. The XRD data show (Fig. $1 \mathrm{~b}$ curve 2) that after annealing at a temperature of $150-300^{\circ} \mathrm{C}$, the intensity of the $\mathrm{Ag}$ (111) peak enhances, indicating an increase in the size and the degree of crystallinity of silver particles. The crystallite size (Table 1), determined by the Rietveld method, sharply increases from 2.5 to $98 \mathrm{~nm}$ as the annealing temperature increases to $200^{\circ} \mathrm{C}$. A further increase in the temperature does not affect significantly the crystallite size, and at $250-300^{\circ} \mathrm{C}$, it almost does not change, which is consistent with the microscopic data. 


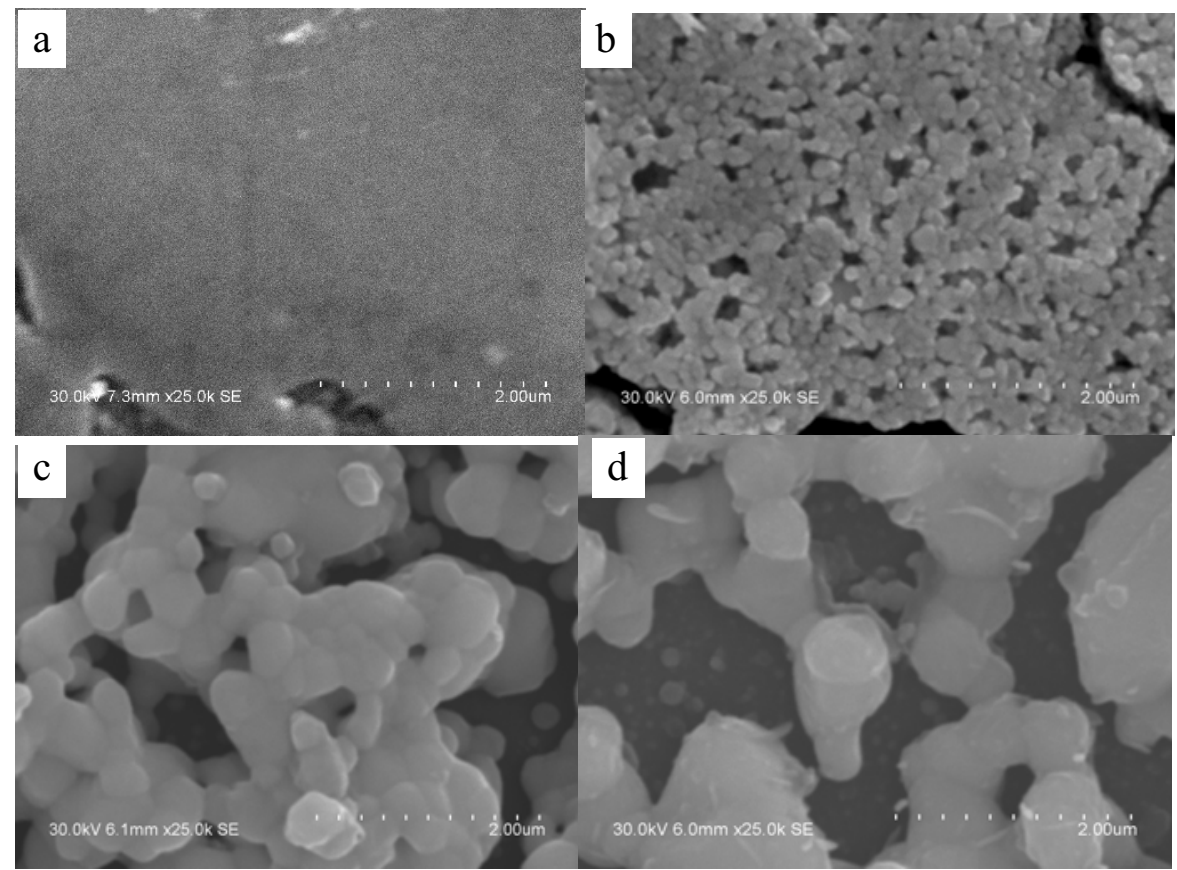

Fig. 2. SEM images of the Ag NPs films before (a) and after thermal sintering in air for $30 \mathrm{~min}$ at $150^{\circ} \mathrm{C}(\mathrm{b}), 200^{\circ} \mathrm{C}(\mathrm{c})$ and $300^{\circ} \mathrm{C}(\mathrm{d})$.

Due to the sintering and interparticle bridging, the films achieved a certain electrical conductivity already at $150^{\circ} \mathrm{C}$. The resistivity of the films annealed at $150^{\circ} \mathrm{C}$ for $30 \mathrm{~min}$ is $5.75 \times 10^{-4} \Omega \cdot \mathrm{cm}$. At $200-250^{\circ} \mathrm{C}$, the resistivity decreases, since further sintering and recrystallization of the individual particles occurs, due to which the percolation path and electrical conductivity increase. The resistivity value $2.8 \times 10^{-5} \Omega \mathrm{cm}$ achieved after sintering at $300^{\circ} \mathrm{C}$, is similar or slightly higher than that reported in the literature $[6,9,14,18]$. At the same time, the value is an order of magnitude higher than that of bulk silver $\left(1.6 \times 10^{-6}\right.$ $\Omega \cdot \mathrm{cm})$. This may be due to the non-homogeneous porous structure of the layer and, possibly, due to the organic residues remained in the film.

Table 1. Ag crystallite size of the Ag NPs films after thermal sintering in air.

\begin{tabular}{|l|l|l|l|l|l|}
\hline Temperature, ${ }^{\circ} \mathrm{C}$ & 25 & 150 & 200 & 250 & 300 \\
\hline Crystallite size, $\mathrm{nm}$ & $2.5(0)$ & $48(1)$ & $98(1)$ & $135(4)$ & $140(4)$ \\
\hline Resistivity, $\Omega \cdot \mathrm{cm}$ & $>10000$ & $5.8 \times 10^{-4}$ & $1.5 \times 10^{-4}$ & $7.3 \times 10^{-5}$ & $2.8 \times 10^{-5}$ \\
\hline
\end{tabular}

Depending on the laser exposure values, the structure and electrical properties of the silver films after laser sintering were investigated. It was found that an increase in the exposure values from 5 to $60 \mathrm{~J} / \mathrm{cm}^{2}$ does not affect strongly the size of the sintered particles which is about $100-200 \mathrm{~nm}$ at high exposures. At the same time, at low exposures, in the range $5-10 \mathrm{~J} / \mathrm{cm}^{2}$, both big individual crystallites and even silver nanowires are observed on the surface of the film (Fig. 3a, b), and small particles of 50-100 nm beneath it in the layer. Apparently, this structure is a result of the uneven heating of the film and a strong temperature gradient over the layer thickness during laser treatment. At high exposures, a continuous layer almost without voids is formed in contrast to that observed during thermal heating (Fig. 3c, d). The XRD data show (Fig. 1 curve 3) that an increase in exposure results in a gradual increase in the intensity of the metallic silver reflections 
indicating that the size of silver particles increases. The crystallite size (Table 2.) gradually increases from 23 to $65 \mathrm{~nm}$, which is consistent with the microscopic data.

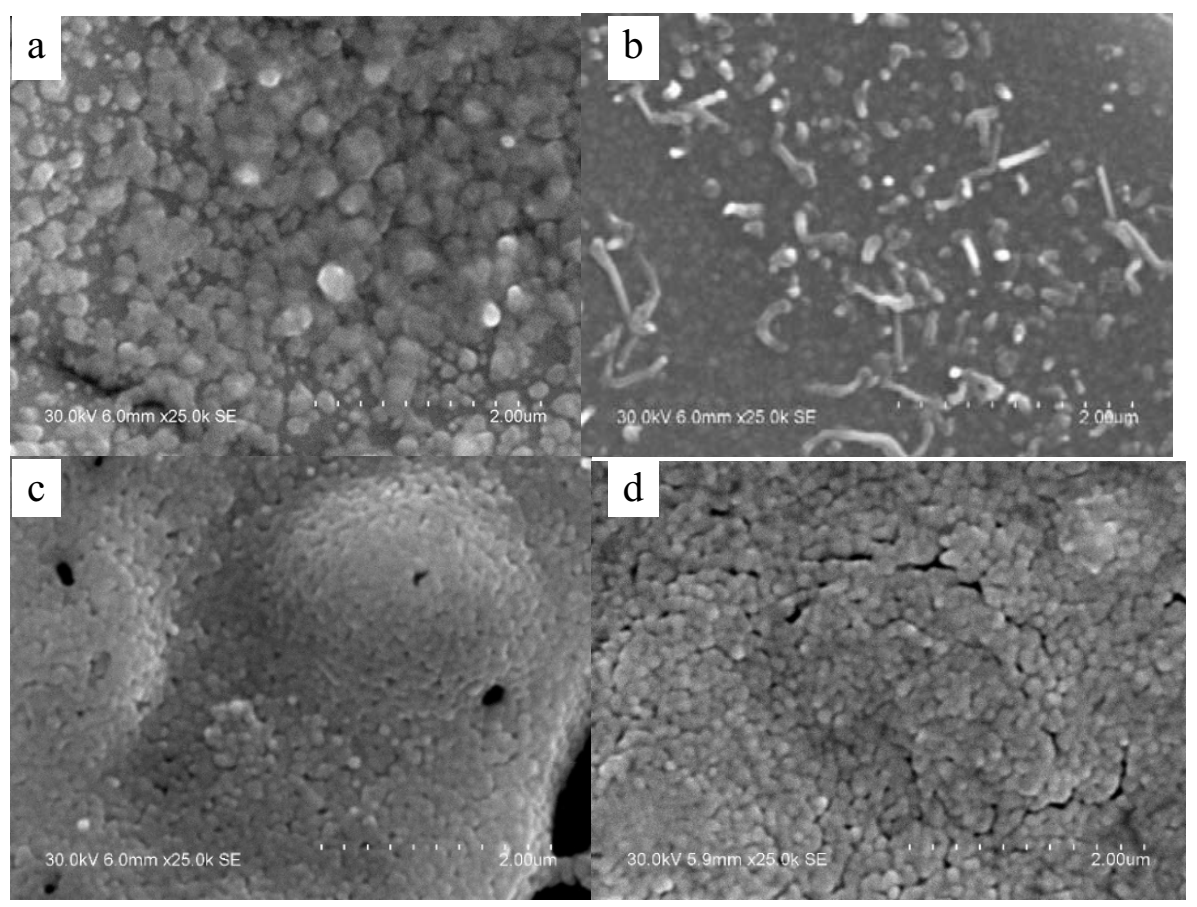

Fig. 3. SEM images of the Ag NPs films after laser sintering at exposure values of $5 \mathrm{~J} / \mathrm{cm}^{2}$ (a), $10 \mathrm{~J} / \mathrm{cm}^{2}$ (b), $20 \mathrm{~J} / \mathrm{cm}^{2}$ (c) and $50 \mathrm{~J} / \mathrm{cm}^{2}$ (d).

At low exposures of 5 and $10 \mathrm{~J} / \mathrm{cm}^{2}$, mainly due to the uncompleted decomposition of the organic component and the particles sintering, the films show relatively high resistivity values of 336.2 and $5.6 \times 10^{-2} \mathrm{Ohm} \cdot \mathrm{cm}$ respectively (Table 2.). At exposures of 20 and 50 $\mathrm{J} / \mathrm{cm}^{2}$, a significant decrease in the resistivity of the sintered silver films occurs (Table 2.). Under these conditions, the organic component is further removed and the resistivity of the resulting films after sintering decreases to $3.0 \times 10^{-4}$ and $2.3 \times 10^{-6} \mathrm{Ohm} \cdot \mathrm{cm}$ respectively. The achieved value $2.3 \times 10^{-6}$ is close to or slightly lower than those reported in the literature $[6,9,14,16,23]$, including the cases of using other types of lasers $[18,20,21]$, and it is close to that of bulk silver.

Table 2. Ag crystallite size after laser sintering of the Ag NPs films in air.

\begin{tabular}{|l|l|l|l|l|}
\hline $\begin{array}{l}\text { Laser exposure, } \\
\mathrm{J} / \mathrm{cm}^{2}\end{array}$ & 5 & 10 & 20 & 50 \\
\hline Crystallite size, $\mathrm{nm}$ & $23(0)$ & $27(0)$ & $45(0)$ & $65(1)$ \\
\hline Resistivity, $\Omega \bullet \mathrm{cm}$ & 336.2 & $5.6 \times 10^{-2}$ & $3.0 \times 10^{-4}$ & $2.3 \times 10^{-6}$ \\
\hline
\end{tabular}

A further increase in the exposure leads to some side effects, such as melting of the substrate and ablation of the silver film, which makes it difficult to assess the film structure and its electrical properties. As seen, in comparison with thermal sintering (Table 1), laser sintering results in a resistivity of an order of magnitude less (Table 2.). As can be seen from the microscopic data, this is due to the uniform surface morphology of the formed film. After laser treatment at an exposure of $50 \mathrm{~J} / \mathrm{cm}^{2}$, even though the layer is composed of 
smaller crystallites, it is more uniform and has no voids and defects. The homogeneity of the layer is particularly important in the layer-by-layer printing of complex 3D objects. Therefore, laser sintering in this case is a promising method to fabricate conductive patterns on various substrates, including flexible polymer ones.

\section{Conclusions}

Silver nanoparticles (Ag NPs) of $\sim 6 \mathrm{~nm}$ in size were synthesized by the reduction of silver 2-[2-(2-methoxyethoxy)ethoxy]acetate by benzyl alcohol acting both as the solvent and reducer. The as-prepared NPs were then dispersed in a mixture of nontoxic solvents without any additional stabilizers to fabricate inks. The silver ink was spin-coated on polyimide polymer films and processed by thermal and laser sintering using a fiber laser operating in the pulse-periodic mode at a wavelength of $1.064 \mu \mathrm{m}$. After thermal annealing at 200$300^{\circ} \mathrm{C}$, the silver films with non-uniform surface morphology and a large fraction of voids, having a relatively high resistivity of $28 \mu \Omega \times \mathrm{cm}$ were obtained. Laser sintering yielded more uniform, without voids and defects layers with a resistivity of $2.3 \mu \Omega \times \mathrm{cm}$. This study showed that laser sintering is a promising method to fabricate conductive $3 \mathrm{D}$ objects on various substrates, including flexible polymer ones.

The research was funded within the state assignment to ISSCM SB RAS (Project No. 0237-20190002).

\section{References}

1. M. Singh, H.M. Haverinen, P. Dhagat, G.E. Jabbour, Adv. Mater. 22, 673 (2010)

2. D. Wang, Y. Zhang, X. Lu, Z. Ma, C. Xie, Z. Zheng, Chem. Soc. Rev. 47, 4611 (2018)

3. A. Kamyshny and S. Magdassi, Chem. Soc. Rev. 48, 1712 (2019)

4. S. Magdassi, A. Bassa,Y. Vinetsky, A. Kamyshny, Chem. Mater. 152208 (2003)

5. X. Zhou, W. Li, M. Wu, S. Tang, D. Liu, Appl. Surf. Sci. 292, 537 (2014)

6. Q. Huang, W. Shen, Q. Xu, R. Tan, W. Song, Mater. Chem. Phys. 147, 550 (2014)

7. A.I. Titkov, N.V.Bulina, A.S. Ulihin, I.K. Shundrina, E.V. Karpova, E.Y. Gerasimov, Y.M. Yukhin, N.Z. Lyakhov, J. Mater. Sci.: Mater. Electron. 28, 2029 (2017)

8. I.-K. Shim, Y.I. Lee, K. J. Lee, J. Joung, Mater. Chem. Phys. 110, 316 (2008)

9. K.J. Lee, B.H. Jun, T.H. Kim, J. Joung, Nanotechnology 17, 2424 (2006)

10. T.Y. Dong, W.T. Chen, C.W. Wang, C.P. Chen, C.N. Chen, M.C. Lin, J.M. Song, I.G. Chen, T.H. Kao, Phys. Chem. Chem. Phys. 11, 6269 (2009)

11. Ê. Ankireddy, S. Vunnam, J. Kellar and W. Cross, J. Mater. Chem. C. 1, 572 (2013)

12. A.L. Dearden, P.J. Smith, D.-Y. Shin, N. Reis, B. Derby, P. O'Brien, Macromol. Rapid Commun. 26, 315 (2005)

13. J.J. Lee, J.C. Park, M.H. Kim, T.S. Chang, S.T. Kim, S.M. Koo, N.C. You, S.J. Lee, J. Cer. Proc. Res. 8, 219 (2007)

14. Y. Dong, X. Li, S. Liu, Q. Zhu, J.-G. Li, X. Sun, Thin Solid Films 589, 381 (2015)

15. A.I. Titkov, O.A. Logutenko, E.Yu. Gerasimov, I.K. Shundrina, E.V. Karpova, N.Z. Lyakhov, J. Incl. Phenom. Macrocycl. Chem. 94, 287 (2019)

16. W. Yang, F. Hermerschmidt, F. Mathies, E.J.W. List-Kratochvil, J. Mater. Sci.: Mater. Electron. 32, 6312 (2021) 
17. J. Niittynen, R. Abbel, M. Mäntysalo, J. Perelaer, U.S. Schubert, D. Lupo, Thin Solid Films 556, 452 (2014)

18. S. Wünscher, R. Abbel, J. Perelaer, U.S. Schubert, J. Mater. Chem. C. 2, 10232 (2014)

19. S.H. Ko, H. Pan, C.P. Grigoropoulos, J.M. Fréchet, C.K. Luscombe, D. Poulikakos, Appl. Phys. A Mater. Sci. Proc. 92, 579 (2008)

20. A.I. Titkov, I.K. Shundrina, R.M. Gadirov, A.V. Odod, A.E. Kurtsevich, Yu M. Yukhin, N.Z. Lyakhov, Mater. Today: Proc. 5, 16042 (2018)

21. A.I. Titkov, R.M. Gadirov, S.Y. Nikonov, A.V. Odod, T.A Solodova, A.E. Kurtsevich, T.N. Kopylova, Yu M. Yukhin, N.Z. Lyakhov, Russ. Phys. J. 60, 1674 (2018).

22. H.M. Rietveld, J. Appl. Cryst. 2, 65 (1969)

23. A.I. Titkov, O.G. Bukhanets, R.M. Gadirov, Yu.M. Yukhin, N.Z. Lyakhov, Inorg. Mater. Appl. Res. 6, 375 (2015) 